\title{
Effects of Transactional Leadership, Psychological Empowerment and Empowerment Climate on Creative Performance of Subordinates: A Cross-level Study
}

(C) Higher Education Press and Springer-Verlag 2010

\begin{abstract}
This research surveyed 101 teams, involving 497 team members and 101 team leaders, in a large multinational company in China. A hierarchical linear model is used to examine the hypothesized mediated moderation model. It is found that: (1) individual psychological empowerment is positively related to creative performance; (2) the relationship between transactional leadership and subordinates' creative performance is moderated by team empowerment climate; (3) individual transactional leadership behavior is positively related to subordinates' creative performance in teams with higher empowerment climate, but negatively related to subordinates' creative performance in lower empowerment climate; and (4) the relationship between transactional leadership, team empowerment climate and creative performance is partially mediated by subordinates' psychological empowerment perception. Theoretical contributions and practical implications are also discussed.
\end{abstract}

Keywords transactional leadership, psychological empowerment, empowerment climate, creative performance, mediated moderation

Translated from Guanli Shijie 管理世界 (Management World), 2009, (4): 135-142

Feng Wei $(\bowtie)$

School of Management, Shanghai University, Shanghai 200444, China

E-mail: fwei@shu.edu.cn

Xin Yuan

Alcatel-Lucent, Shanghai 201206, China

E-mail: Xin.yuan@alcatel-lucent.com

Yang Di

Alcatel-Lucent, Shanghai 201206, China

E-mail: Yang.di@alcatel-lucent.com 


\section{Introduction}

To survive and succeed in a competitive business environment, organizations nowadays must constantly seek out new technologies, products and markets (Amabile, 1988; Mumford, Scott, Gaddis, and Strange, 2002). This trend applies not only to organizations in developed countries but also to those in developing countries. In recent years, lack of innovation has limited Chinese enterprises' ability to enhance their international competitiveness. Chinese enterprises will not be successful in the global competitive environment, unless they can break through the traditional patterns of business and operation, develop independent innovative competences, and eventually compete based on quantity and quality simultaneously. In order to explore how Chinese organizations prompt innovations, we must first identify how to improve individual creativity because organization innovation is a product of individuals' creative performance.

Organizational innovative behaviors, typically, are affected by two factors, namely, provision of leadership (e.g., Tierney, Farmer and Graen, 1999) and cultivation of an enabling climate (e.g., Scott and Bruce, 1994).

Thus, leadership is one of the key drivers of followers' effective work behaviors. However, not all leadership behaviors are equally effective. In fact, findings show that transformational leadership is related to followers' creative performance. Yet there are also studies reporting conflicting findings, especially on transactional leadership (e.g., Basu and Green, 1997; Sosik, Kahai and Avolio, 1998; Jung, 2001). Another management approach to promote innovation is through the cultivation of an empowering climate. Recently, Seibert, Silver and Randolph (2004) focused on a group variable called empowerment climate, a construct which is different from the subjective nature of psychological empowerment, and is also found to be related to followers' creativity.

To date, no research has been conducted to investigate the combined forces of transactional leadership and empowerment climate and the process through which they impact followers' creative performance. This study aims to examine a complex process through which the relationship between transactional leadership and followers' creative performance can be moderated and mediated by empowerment at both group and individual levels. Findings of this cross-level study can extend our understanding of critical antecedents to employees' innovation.

\section{Theories and Hypotheses}

\subsection{Transformational Leadership Theory}

In the past two decades, much attention has been directed to the transformational 
leadership theory (Judge and Bono, 2000). In particular, Bass (1985) made a great contribution to the development of this theory by conceptualizing the constructs of transformational leadership and transactional leadership in a more systematic manner, which offers researchers basic concepts and a complete framework.

Bass (1985) proposed that theories of leadership should understand how leaders influence their subordinates to achieve the highest level of performance mainly for more profits of his/her department or organization rather than his/her own interests, by focusing on the clarity of a subordinate's role and goals and using rewards and punishment according to the subordinate's behaviors. $\mathrm{He}$ argued that transactional leadership is a mutual exchange-process based on the performance of promissory obligations, typified by goal-setting, supervisory control and output control. Transactional leadership is characterized by the following three factors: (1) contingent rewards, a style of leadership which provides material and mental rewards according to the completion of promised obligations by subordinates, based upon specific role and task requirement. (2) active management-by-exception, which refers to a style of leadership whereby the leader carries out positive supervision of performance to avoid mistakes. (3) passive management-by-exception, a style of leadership whereby the leader intervenes only after the appearance of behaviors or mistakes against the requirements. Both forms of management-by-exception result in the leader's attempt to achieve the expected level of performance by preventing or correcting individual mistakes.

Although transactional leaders utilize transformational strategies at appropriate moments, they mostly motivate subordinates by means of predicting the future and depicting the vision.

The transactional leadership has a predictable impact on innovation behaviors and performance. The transactional leader often assigns tasks to subordinates by the law of "the correct way leads to success", placing an emphasis on performing tasks as they have been performed in the past and using methods that a routine and predictable; thereby reducing the potential for creative performance.

\subsection{Psychological Empowerment Theory}

Empowerment in organizations has gained a lot of attention from scholars over the years. Lee and Koh (2001) suggested that empowerment involves two concepts: first, the "objective behavior" conducted by the supervisor to the subordinates, which was called managerial empowerment. Second, the "subjective psychological state" perceived by the subordinates toward the empowerment, which was called psychological empowerment. Research on the psychological empowerment involves two levels. One level is the individual 
psychological empowerment research that gradually developed on the basis of the generally recognized measurements developed by Spreitzer (1995a); and the other level is the empowerment climate research, which originated in the classical demonstration of team empowerment. Research on empowerment climate has been increasing due to the highly popularized cross-level research in the recent years.

Psychological empowerment is a psychological state of a subordinate resulting from empowerment practices (Spreitzer, 1992; Thomas and Velthouse, 1990). Psychological empowerment has been conceptualized as a multidimensional construct consisting of impact (i.e. degree to which employees feel their work affects the effectiveness of their organization), competence (i.e. perceived ability to perform their tasks well), meaningfulness (i.e. belief that their work is important), and self-determination (i.e. perceived autonomy at work) (Kirkman and Rosen, 1997, 1999; Spreitzer, 1995, 1996; Thomas and Velthouse, 1990).

Through an 8-year study of 10 organizations, Randolph (1995) proposed a macro view of empowerment called empowerment climate. He identified three sets of organizational practices which are essential to empowerment climate. The three key practices are: information sharing, autonomy through boundaries, and team accountability. With information sharing, employees are provided with strategic business information on costs, productivity, quality, and financial performance of the organization. The practice of autonomy through boundaries encourages employees to develop work goals, procedures and areas of responsibility independently. Finally, team accountability delegates the locus of decision-making to the teams.

Psychological empowerment differs from empowerment climate is that the later emphasizing on the process of delegating of authorities whereas the former has more to do with enabling a heightened sense of self and motivation at work (Lee and Koh, 2001). Organizations can delegate duties and responsibilities down the hierarchy. However, the act of delegation does not necessarily mean that the delegated employees will feel empowered.

\subsection{Psychological Empowerment and Creative Performance}

Empowered followers see the meaning of their jobs and meaning serves as the "engine" to energize them to achieve something of significance (Spreitzer, et al., 1997). They are further energized if they see their works will make an impact and contribute to the achievement of collective goals. Also, followers who feel competent develop strong confidence in self and they would actively develop their work competence and eagerly seek ways to improve their work and work conditions (Spreitzer, 1995b). Those who feel efficacious are more cognitively flexible and likely to find many alternative ways of solving problems. This 
renewed sense of work meaning, awareness of one's impact on collective goals, and work competence will have strong effects on creative activities. All these are further reinforced by followers' feelings of self-determination and eagerness to make an impact on their works and organizations. Self-determination is an important determinant of organizational creativity because individuals produce more creative work when they perceive more personal control over how to accomplish given tasks (Jung and Sosik, 2002).

Prior research in the creativity and empowerment literature has indicated a positive relationship between psychological empowerment and creativity. For example, Amabile (1983) found that people perform more creatively if they are motivated by interest in the activity itself, rather than the promise of rewards or threat of punishments. Creative performance, Amabile discovered, is facilitated by giving individuals high levels of discretion, especially in the use of time. In other words, conditions that allow an individual to work in accordance with their own creative process - against their own internal standards-encourage and nurture creative performance. Bandura's (1982) research indicates an individual's self-evaluation of their capacity to succeed-what he calls self-efficacy - is closely related to intrinsic motivation, and thus creative performance. Spreitzer, DeJanasz and Quinn (1999), for example, found that supervisors who felt more empowered were seen as being more innovative (creative) by their subordinates. Quinn and Spreitzer (1997) concluded that empowered employees tended to experiment, to look at old problems from new approaches and produce creative/innovative outcomes. Therefore, we predict the following hypothesis:

H1 Psychological empowerment is positively related to creative performance.

\subsection{Transactional Leadership and Creative Performance}

Creativity is a process of destroying established rules to develop new ones, which breaks through and reforms the various limited conditions, and it indicates the reform of the elements which have already existed. Past research results claimed that individual intrinsic-motivated behavior is an important factor to facilitate creativity (Amabile, Conti, Coon, Lazenby and Herron, 1996; Deci and Ryan, 1985) and individual creative performance requires not only the promotion of external force but also the stimulation of an individual's intrinsic motivation.

According to the transformational leadership theory, a transactional leader (Bass, 1985) is recognized as the person who has influence in the existing system and culture, and he or she takes delight in avoiding risks, emphasizing more the limits of time and efficiency, and taking control of the performance process rather than the content itself. Consequently, there is a strong likelihood 
that transactional leaders are more effective in predictable circumstances when a detailed plan is the most effective strategy and when the leader can easily satisfy the subordinates' needs through an exchange only if their performances achieve the basic expectation. In a team under the charge of a transactional leader, subordinates' freedoms are constrained so that there is little opportunity for self-determination or creativity. Evidence from previous empirical research studies also supports this conclusion. For example, analyses of transactional leadership revealed that contingent rewards have a destructive influence on the creative performance (e.g., Amabile, Hennessey and Grossman, 1986; Eisenberger and Shanock, 2003). Jung (2001) found that subordinates who are under the control of a transactional leader will show less creativity than the ones who are under the control of a transformational leader. Lee (2008) discovered a negative relationship between transactional leadership and the subordinate's creative performance. We therefore tested the following hypothesis:

H2 Transactional leadership is negatively related to subordinates' creative performance.

\subsection{The Moderation of Team Empowerment Climate}

Randolph (1995) argued that in a team with insufficient empowerment climate, team members, in turn, lack intrinsic motivation or a desire to undertake greater responsibilities and accept challenges. Their response to the environment is passive rather than active, and their achievement of work goals heavily relies on other internal factors of the team. Meanwhile, their creative thoughts and motivation greatly depend on other factors such as leadership, yet they only obtain a little support for the team empowerment climate. In the team of low-level empowerment climate, the transactional leadership suffering from "weak disturbance" of the low-level empowerment climate will have an influence on the subordinates' creative performance. Consequently, the negative relationship between transactional leadership and the subordinates' creative behaviors will be even worse when team empowerment climate is low. Information sharing will be limited, tense relations among the members will exist, and supervisors will exert comparatively more control on the individual behaviors.

On the contrary, in the team with sufficient empowerment climate, there is a higher level of trust among team members, more frequent flow of information, more open team goals, and less supervisory control from the managers. The result is greater feelings of respect, more self-determination, more sense of common values, and more harmonious work climate, leading to more intrinsic motivation and willingness, and thus, more creative performance. In such 
climates, the transactional leaders suffering from "strong disturbance" of the high-level empowerment climate will have little influence on the subordinates' creative performance. In high-level team empowerment climates, the enthusiasm and self-determination stimulated by the high-level empowerment climate will supply a gap or remedy to the negative effect of transactional leaders on the subordinates' creative performance. Therefore, we predict a moderated effect, as shown in the following hypothesis:

H3 Team empowerment climate moderates transactional leadership-subordinates' creative performance relationship in such a way that the relationship is negative when empowerment climate are low and positive when they are high.

\subsection{The Mediated Moderation of Empowerment Climate and Psychological Empowerment}

To be creative is essentially an individual processes. To the extent that individuals become creative partially depends on the specific opportunities and constraints of the environment. Nevertheless, individuals' creative behaviors are not entirely influenced by contextual forces such as leadership or climate. External influences remain external to these individuals if these influences have not been registered in their hearts and minds. Piaget (1972) argues that individuals possess schemas which actively assimilate external stimuli and convert them to fit their existing cognitive structure. The structure, as a result of the newly assimilated inputs, may need to modify itself. In this regard, both transactional leadership and empowerment climate serves as external stimuli to promote creative behaviors.

But it is the individuals who reconstruct these external stimuli and assimilate them in a way which fits their internal needs of a coherent balance. Empowered followers are further energized if they see their works will make an impact and contribute to the achievement of collective goals. Also, followers who feel competent develop strong confidence in self and they would actively develop their work competence and eagerly seek ways to improve their work and work conditions (Spreitzer, 1995b). Spreitzer, et al. (1997) found that psychologically empowered employees are more satisfied with their jobs, less likely to experience stress than those who do not feel empowered and psychological empowerment is in fact mediates the relationship between organizational social structure and behavioural outcomes (Spreitzer, 1995b). Based on the above discussions and the logic of $\mathrm{H} 1$ and $\mathrm{H} 3$, we hypothesize that:

H4 Psychological empowerment mediates the interactive effects of the transactional leadership and empowerment climate on followers' creative performance. 


\section{Methods}

\subsection{Sample}

The sample used in this study consisted of 150 teams, including 750 team members and 150 team leaders, in a large multinational communication company with more than 10000 employees, based in Shanghai City of China. Two sets of questionnaires were used: one for subordinates and another for their immediate supervisor. The questionnaires were administered to the employees and supervisors of the groups respectively. The respondents received a questionnaire, a return envelope, and a cover letter of introduction to the survey that we prepared. Each questionnaire was coded with a researcher-assigned identification number to match employees with their immediate supervisor. To ensure confidentiality, the respondents were instructed to seal the completed questionnaires in the return envelopes and return them directly to researcher on-site. Out of the 900 questionnaires distributed (150 to supervisors and 750 to subordinates), 101 usable teams with 497 subordinates and 101 supervisors were returned, with a response rate of $68 \%$.

\subsection{Measures}

Transactional leadership. Bass and Avolio's (1995) multifactor leadership questionnaire (MLQ) form $5 \mathrm{X}$ was adopted, in which 10 items measuring the transactional leadership. The questionnaire required subordinates to rate their direct supervisor's leadership styles on a seven-point scale ranging from 1 (not at all) to 7 (frequently, if not always). Sample items in the dimensions include: "My supervisor tells me what I will receive if I do as required" (contingent reward leadership), "My supervisor focuses his/her attention on irregularities, mistakes, exceptions and deviations from what is expected of me" (management-by-exception active leadership), "My supervisor won't take action until the situations worsens" (management-by-exception passive leadership). The Cronbach's alpha was 0.81 .

Empowerment climate. Blanchard, Carlos, and Randolph's (1995) empowerment barometer was used to measure the empowerment climate of each team. All participants were instructed to reflect on their perception of the climate on a 7-point Likert scale ranging from 1 (never) to 7 (always). The measure reflects three subscales: information sharing, autonomy through boundaries, and team responsibility and accountability. Each subscale consists of 10 items. Sample items in the dimensions are: "We receive the information that helps us know the performance of our organization"; "We share a common vision for our organization at all levels of the organization"; 
"We view teams as the focal point of responsibility and accountability in our organization". The Cronbach's alpha was 0.96 .

Psychological empowerment. Spreitzer's (1995a) 12 items scale measuring four dimensions of psychological empowerment was used. The dimensions are meaning, competence, impact and self-determination. Sample items include "My job activities are personally meaningful to me", "I am confident about my ability in my job", "I can decide on my own on ways to finish my work" and "I could influence the decisions of my team". All participants were instructed to reflect on their perception of the climate on a 7-point scale ranging from 1 (never) to 7 (always). The Cronbach's alpha was 0.94 .

Creative performance. We used the 8 items retained from the measure of George and Zhou's (2001) for creative behavior. The questionnaire was administered to supervisors to assess their subordinates' creative performance. All participants were instructed to reflect on their perception of subordinates' performance on a 7-point scale ranging from 1 (never) to 7 (always). One sample item in the dimensions is: He/she comes up with new and practical ideas to improve performance. The Cronbach's alpha was 0.95 .

The original questionnaire was in English and was translated from English into Chinese by a bilingual speaker of Chinese and English. The Chinese questionnaire was then given to another bilingual speaker to back-translate into English. In cases where the back-translation was not equivalent to the original version, the process of translation was repeated once.

\subsection{Analysis Methods}

We tested $\mathrm{H} 4$ as proposed by the mediated moderation model, using the three multi-level linear regression equations specified by Muller, Judd and Yzerbyt (2005), which operationally define Baron and Kenny's (1986) conceptualization of mediated moderation. In the first equation, all control variables, the independent variables (i.e., transactional leadership and empowerment climate) and the leadership-climate interaction term were regressed on creative performance. The second equation was designed regressing psychological empowerment on the same set of control variables, independent variables and the interaction term. The final equation regress creative performance, in addition to the same set of variables as in the equation 1 and 2 , on psychological empowerment.

\subsection{Data Aggregation}

Both James, Demaree and Wolf (1993) (Rwg) and intra-class correlation (ICC) (Bliese, 2000) as computed through a random intercepts model indicated the 
proportion of total variance between teams. The median Rwg value for empowerment climate $(0.97)$ was above the recommended criterion of 0.70 (James, Demaree and Wolf, 1993; Klein \& Kozlowski, 2000). The ICC values for empowerment climate (ICC1 $=0.19, \mathrm{ICC} 2=0.54)$ were all statistically significant. The ICC1 values were generally above the recommended level of 0.12 (James, 1982) and the ICC2 values were above the recommended cutoff value of 0.47 (Schneider, White and Paul, 1998).

\section{Results}

Means, standard deviations, and zero order Pearson correlations among all variables in this study are presented in Table 1. Both transactional leadership and empowerment climate were positively related to creative performance (i.e. $r=0.29, p<0.001$ and $r=0.40, p<0.001$, respectively). The two independent variables also had strong correlations with the mediator variable-psychological empowerment ( $r=0.35, p<0.001$ and $r=0.43, p<0.001$, respectively). Psychological empowerment, in turn, was found to relate to creative performance $(r=0.51, p<0.001)$. Findings provided support to our proposed model.

Table 1 Means, Standard Deviations, and Correlations of Study Variables

\begin{tabular}{lcccccc}
\hline Variables & Mean & S.D. & 1 & 2 & 3 & 4 \\
\hline 1. Psychological empowerment & 5.11 & 0.97 & $(0.94)$ & & & \\
2. Transactional leadership & 3.71 & 0.83 & $-0.35^{* * *}$ & $(0.81)$ & & \\
3. Empowerment climate & 4.11 & 0.86 & $0.43^{* * *}$ & $-0.31^{* * *}$ & $(0.96)$ & \\
4. Creative performance & 4.85 & 1.04 & $0.51 * * *$ & $-0.29 * * *$ & $0.40^{* * *}$ & $(0.95)$ \\
\hline
\end{tabular}

Note: Reliability coefficients for the scales are in parentheses along the diagonal.

* indicates significant at 0.05 level, ** indicates significant at 0.01 level, *** indicates significant at 0.001 level.

Table 2 provides a summary of the models and results used to test $\mathrm{H} 1$ to $\mathrm{H} 4$. Three multilevel regression models were considered, with the effects of gender, education and organizational tenure being controlled at the individual level. Model 1 depicts the impact of transactional leadership at the individual level, empowerment climate at the group level and the interactive effects of the both, regressing on creative performance. Findings revealed creative performance is negatively related to transactional leadership $(\beta=0.06, p<0.05)$ and positively to empowerment climate* transactional leadership $(\beta=0.26, p<0.001)$. Hence, $\mathrm{H} 2$ and $\mathrm{H} 3$ are supported. 
Table 2 Hierarchical Linear Modeling for Testing the Mediated Moderation of Creative Performance

\begin{tabular}{|c|c|c|c|}
\hline Variables & $\begin{array}{l}\text { Model 1: } \\
\text { Creative } \\
\quad \text { performance }\end{array}$ & $\begin{array}{l}\text { Model 2: } \\
\text { Psychological } \\
\text { empowerment }\end{array}$ & $\begin{array}{l}\text { Model 3: } \\
\text { Creative } \\
\quad \text { performance }\end{array}$ \\
\hline \multicolumn{4}{|l|}{$\begin{array}{l}\text { Individual level } \\
\end{array}$} \\
\hline Gender & 0.13 & 0.04 & 0.11 \\
\hline Education & -0.03 & -0.05 & -0.03 \\
\hline Tenure & -0.04 & -0.03 & -0.02 \\
\hline Transactional leadership & $-0.06^{*}$ & $-0.12 * *$ & -0.02 \\
\hline$\Delta R^{2}$ & 0.08 & 0.17 & 0.08 \\
\hline \multicolumn{4}{|l|}{ Team level } \\
\hline Empowerment climate & $0.24 * * *$ & $0.44 * * *$ & $0.27 * * *$ \\
\hline$\Delta R^{2}$ & 0.11 & 0.28 & 0.11 \\
\hline \multicolumn{4}{|l|}{ Interactive effect } \\
\hline $\begin{array}{l}\text { Transactional } \\
\text { leadership } \times \text { Empowerment climate }\end{array}$ & $0.26 * * *$ & $0.11 * *$ & $0.21 * * *$ \\
\hline$\Delta R^{2}$ & 0.15 & 0.09 & 0.15 \\
\hline \multicolumn{4}{|l|}{ Mediator } \\
\hline Psychological empowerment & & & $0.18 * *$ \\
\hline$\Delta R^{2}$ & & & 0.03 \\
\hline
\end{tabular}

Model 3 shows that psychological empowerment is positively related to creative performance $(\beta=0.18, p<0.01)$ and fully mediated the effect of transactional leadership on creative performance (i.e. reducing from $\beta=-0.06$, $p<0.05$ to $\beta=0.02$, n.s.) but not the effect of empowerment climate on employee innovation. There was no reduction of effect size after psychological empowerment was entered into the model.

We found that the significant joint effect of leader and climate on creative performance is now reduced from $(\beta=0.26, p<0.001)$ to $(\beta=0.21, p<0.001)$. The reduction of moderated effect is thus said to be partially mediated by psychological empowerment. To test whether the interaction effect of transactional leadership and empowerment climate significantly reduced upon the addition of psychological empowerment, we performed the Sobel test (Baron and Kenny, 1986; Sobel, 1982), which revealed that psychological empowerment significantly mediated the interaction effect of transactional leadership and empowerment climate on creative performance $(t=8.92, p<0.001)$. To conclude, results provided support for $\mathrm{H} 1$ and $\mathrm{H} 4$.

To interpret the interaction effect on creative performance in Table 2, we considered two levels of leadership behavior and two levels of empowerment climate by taking the standard deviation from its own mean and forming high and low levels of leadership behavior and of empowerment climate. Fig. 1 shows 
that when the empowerment climate is low, a supervisor who displays transactional leadership behavior reduces subordinates' creative performance; when the empowerment climate is high, transactional leadership behavior enhances subordinates' creative performance.

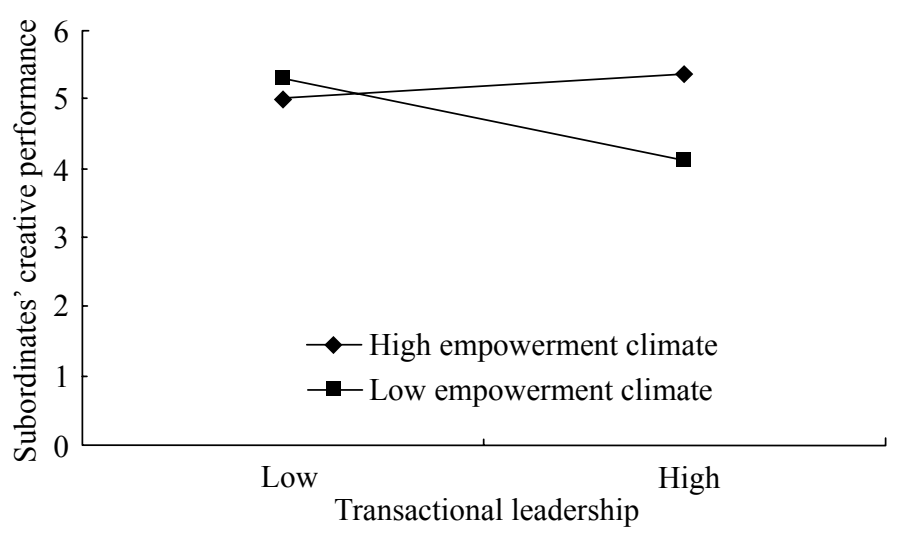

Fig. 1 Empowerment Climate as a Moderator of Transactional Leadership-Subordinates' Creative Performance Relationship

\section{Discussion}

\subsection{Transactional Leadership: Positive or Negative Factor?}

Past research on the leadership effectiveness has revealed that leadership can be classified into positive and passive ones. Transformational leadership and contingent rewards have been recognized as active leadership, while the non-interference leadership has been regarded as passive leadership. For example, Judge and Piccolo's (2004) meta-analysis revealed that transformational leadership, contingent rewards and active management by exception are positive predictors of leader effectiveness, while passive management by exception and the non-interference leader are negative predictors. Researchers in China have drawn different conclusions. For example, Lee and Wei's (2008) research suggested that the positive impact of the contingent reward on the leadership effectiveness is not significant in any context, and management by exception has either positive or negative relationship with it. However, the above conclusions, in general, support the impact of most factors of transactional leadership on the leadership effectiveness.

However, it is necessary to point out that the indexes of leadership effectiveness in the past were such things as satisfaction, performance, organizational commitment, and extra efforts, but not including creative performance. The present study investigating the relationship between transactional leadership and creative 
performance finds that transactional leadership is a destructive power to the subordinates' creative performance. Accordingly, with respect to creative performance, transactional leadership is in the domain of passive leadership.

In the management practice of organizations, transactional leadership is so common that managers should not only understand the negative influence of this behavior on creative performance, but also accept it, especially for the active effect of contingent rewards on other indexes of the leadership effectiveness (e.g., the leadership satisfaction, organizational commitment, and OCB). In fact, even with the negative effect on subordinates' creative performance, in most cases, transactional leadership is still a relatively effective leadership style that deserves recommendations for management. However, if an organization pays more attention to the creative performance, it is necessary for the organization to use other ways to cover the gap created by the destruction of transactional leadership.

\subsection{Team Empowerment Climate: Substitutes or Principal?}

Much prior research on leadership has consistently focused on leaders and the leadership effectiveness. For instance, trait-related leadership theories hold that the leader's performance depends on the leader's unique qualities and unconventional skills; behavioral theories of leadership assume that the leader's performance depends on the leader's proper behaviors of leadership; and a series of empirical studies repeatedly demonstrated the effect of the leader's personal power on innovation (e.g., Deci and Ryan, 1985; Amabile et al., 1996; Krause, 2004; Lee, 2008). However, the conclusion of this study provides a new perspective. Specifically, team empowerment climate can serve as a substitute for transactional leadership.

The best interpretation of this phenomenon is Kerr and Jermier's (1978) theories of substitute for leadership. The theory emphasizes the determinant influence of a formal leader on the subordinates' work performance. Substitutes for leadership theories state that specific situational factors can substitute or neutralize the supervisor's leadership and thereby influence the subordinates' work performance. Kerr and Jermier (1978) advanced the ideas, stating that not all motivation and restriction requires the leader's personal behaviors, and other sources (e.g., the subordinate's personal traits, job and task characters, organization and team system, culture and climate) can also provide instruction, recognition, motivation and inspiration. In such cases, employee's need for the formal leader is low, and the "substitute for leaders" will take place, which results in the failure of the effect of behaviors of leadership (Dionne, Yammarino, Howell and Villa, 2005). In this theory, the environment variable involves two factors: leadership substitute and leadership neutralizer. The former refers to instances when the influence of the formal leader is replaced, resulting in its 
impossibility and lack of necessity. In contrast, the latter refers to instances when the influence of the formal leader is blocked or weakened, thereby limiting or eliminating its potential effect.

This study finds that team empowerment climate is a substitute for personal leadership behavior in the context of creative performance, preventing the passive influence of transactional leadership. Thus, the correct viewpoint of the impact of leader behaviors is: pay attention to the various effects of different behaviors of leadership on subordinates' creative performance, strive to improve the leader's behavior; focus on cultivating a team empowerment climate.

\subsection{Implications for Theory and Practice}

This research contributes to leadership theories in two aspects. First, the results presented here help in the "search for a needle in a haystack" as discussed by Podsakoff, MacKenzie, Ahearne and Bommer (1995). They have suggested that the basic emphasis of leadership research should be to identify and describe the moderating role of situational variables on the relationship between leader behaviors and subordinate outcomes. They concluded that till then, few conclusion has been drawn and that more work was needed in this area. This paper helps advance their research by identifying team empowerment climate as a significant situational factor and by uncovering the role it plays in moderating the impact of transactional leadership on creative performance.

Second, this study is a useful response to the demand for cross-level research in the field of leadership. In recent years, there has been a significant appeal for cross-level research (Cole and Bedeian, 2007; Mumford, Campion and Morgeson, 2007). However, Yammarino, Dionne, Chun and Dansereau (2005) found that little research in the field of leadership involves the analysis of levels in spite of the tremendous amount of leadership research and abundant achievements. The results presented here helped fill that void.

In both cases of leadership and climate, we find followers' psychological empowerment playing a critical mediating role. This is more in the case of transactional leadership where the energizing power of transactional leadership does not impact followers' creative performance directly, but will be screened through by individuals' inner sense of empowerment. If for some reasons, individuals fail to feel empowered, then a leader can hardly influence innovative outcome. In fact, leadership may be just one of the many possible sources of influence on their creative performance. One noted source found in this study is empowerment climate. To reinstate, creativity is essentially an individual processes. Instead of being passively influenced by leaders or structural work design features, individuals would actively scan the environment for any constraints and opportunities for innovation. External influences would remain 
external to these individuals if these influences have not been assimilated to their existing cognitive schemas. In order to understand how and why followers would become more psychological receptive to the influence of their leaders and other contextual factors, we should examine individuals' social schemas and unfold the process of adaptation through the interplay of both external and internal forces.

The implications for the application of this research to practice are: First, the conclusions clarify the negative effects of the transactional leadership on the subordinates' creative performance, and provide managers with ideas for improving innovation and its management or control. Specifically, the negative influence of transactional leadership should be prevented. In practice, by selecting the occasion for rewards and cultivating the capability of flexibility, the leader can utilize the advantage of transactional leadership and avoid the passive influence of over rewarding or lack of principles on the organization creative performance.

Second, the substitution effect and moderating effect of team empowerment climate on the relationship between leadership style and creative performance also offers some useful advice to managers. Actively building an empowerment climate is a useful method for promoting creative performance separate from the behavior of leadership. In practice, we can establish the trust relationship and enhance self-management through information sharing, gradually strengthening the subordinates' self-determination and capabilities by means of replacing hierarchy for team.

\subsection{Limitations and Directions for Future Research}

The first limitation of this study is that it is a cross-sectional study, which lacks support from data of time sequence and corresponding experiment design. Therefore, more complicated research design such as the using of time series on the problem is a direction in the future. Second, all of the samples in this study originated from the same organization, which could result in an unfavorable influence on the external validity of conclusions. Future research could be more abundant and diversified in sample design. Third, the measure of the behavioral style of leadership could be expanded. For example, there still remains space for further research upon direct leadership and empowering leadership, which generally exist in Chinese organizations. Studies examine the effects of different leadership forms on creative performance may yield valuable findings for both leadership theory and practice.

\section{References}

Amabile T M (1988). A model of creativity and innovation in organizations. In: Stow B M \& L. 
L. Cummings L L (eds.), Research in Organizational Behavior, Vol.10. Greenwich, Conn: J.A.I. Press, 123-167

Amabile T M, Conti R, Coon H, Lazenby J, Herron M (1996). Assessing the workplace for creativity. Academy of Management Journal, 39: 1154-1184

Amabile, T M, Hennessey B A, Grossman B S (1986). Social influences on creativity: The effects of contracted-for reward. Journal of Personality and Social Psychology, 50: 4-23

Bandura A (1982). Self-efficacy mechanism in human agency. American Psychologist, 37: 122-147

Baron R M, Kenny D A (1986). The moderator-mediator variable distinction in social psychological research: Conceptual, strategic and statistical considerations. Journal of Personality and Social Psychology, 6: 1173-1182

Bass B M (1985). Leadership and performance beyond expectations. New York: Free Press

Bass B M, Avolio B J (1995). MLQ Multifactor Leadership Questionnaire Sampler Set: Technical Report, Leader Form, and Scoring Key for MLQ Form 5x-Short. Redwood City, CA: Mind Garden

Basu R, Green S G (1997). Leader-member exchange and transformational leadership: An empirical examination of innovative behaviors in leader-member dyads. Journal of Applied Social Psychology, 27: 477-799

Blanchard K H, Carlos J P, Randolph W A (1995). The empowerment barometer and action plan. Escondido, CA: Blanchard Training and Development

Bliese P D (2000). Within-group agreement, non-independence, and reliability: Implications for data aggregation and analysis. In: Klein K J \& Kozlowski S W J (eds.), Multilevel Theory, Research, and Methods in Organizations. San Francisco, CA: Jossey-Bass, 349-381

Cole M S, Bedeian A G (2007). Leadership consensus as a cross-level contextual moderator of the emotional exhaustion-work commitment relationship. Leadership Quarterly, 18: 447-462

Deci E, Ryan R (1985). The support of autonomy and control of behavior. Journal of Personality and Social psychology, 53: 1024-1037

Dionne S D, Yammarino F J, Howell J P, Villa J R (2005). Substitutes for Leadership, or Not? Leadership Quarterly, 16 (1): 169-193

Eisenberger R, Shanock L (2003). Rewards, Intrinsic Motivation, and Creativity: A Case Study of Conceptual and Methodological Isolation. Creativity Research Journal, 15: 121-130

George J M, Zhou J (2001). When openness to experience and conscientiousness are related to creative behavior: An interactional approach. Journal of Applied Psychology, 86(3): $513-524$

James L R (1982). Aggregation bias in estimates of perceptual agreement. Journal of Applied Psychology, 67: 219-229

James L R, Demaree R J, Wolf G (1993). Rwg: An assessment of within-group interrater agreement. Journal of Applied Psychology, 78: 306-309

Judge T A, Piccolo R F (2004). Transformational and transactional leadership: A meta-analytic test of their relative validity. Journal of Applied Psychology, 89(5): 755-768

Judge T A, Bono J E (2000). Five-factor model of personality and transformational leadership. Journal of Applied Psychology, 85: 751-765

Jung D I, Sosik J J (2002). Transformational leadership in work groups: The role of empowerment, cohesiveness, and collective-efficacy on perceived group performance. Small Group Research, 33(3): 313-336

Jung D I (2001). Transformational and transactional leadership and their effects on creativity in groups. Creativity Research Journal, 13(2): 185-195 
Kerr S, Jermier J M (1978). Substitutes for leadership: Their meaning and measurement. Organizational Behavior and Human Performance. 22(3): 375-403

Kirkman B L, Rosen B (1997). A model of work team empowerment. Research in Organizational Change and Development, 10: 131-167

Kirkman B L, Rosen B (1999). Beyond self-management: Antecedents and consequences of team empowerment. Academy of Management Journal, 42: 58-74

Klein K L, Kozlowski S W J (2000). From micro to meso: Critical steps in conceptualizing and conducting multi-level research. Organizational Research Methods, 3: 211-236

Krause D E (2004). Influence-based Leadership as a determinant of the inclination to innovate and of innovation-related behaviors: An Empirical investigation. Leadership Quarterly. 15(1): 79-102

Lee J (2008). Effects of leadership and leader-member exchange on innovativeness. Journal of Managerial Psychology, 23(6): 670-687

Lee M, Koh J (2001). Is empowerment really a new concept? International Journal of Human Resource Management, 12: 684-695

Lee J, Wei F (2008). Uncover the black-box of leadership effectiveness: Leader-member exchange as the mediator. Frontiers of Business Research in China, 2: 240-255

Muller D, Judd C M, Yzerbyt V Y (2005). When moderation is meditated and when mediation is moderated. Journal of Personality and Social Psychology, 89(6): 852-863

Mumford M D, Scott S M, Gaddis B, Strange J M (2002). Leading creative people: Orchestrating expertise and relationships. Leadership Quarterly, 13: 705-750

Mumford T V, Campion M A, Morgeson F P (2007). The leadership skills strataplex: Leadership skill requirements across organizational levels. Leadership Quarterly 18: $154-166$

Piaget J (1972). The Principles of Genetic Epistemology. London: Routledge \& Kegan Paul.

Podsakoff P M, MacKenzie S B, Ahearne M, Bommer W H (1995). Searching for a needle in a haystack: Trying to identify the illusive moderators of leadership behaviors. Journal of Management, 21(3): 422-470

Quinn R E, Spreitzer G M (1997). The road to empowerment: Seven questions every leader should consider. Organizational Dynamics, 26(2): 37-49

Randolph W A (1995). Navigating the journey to empowerment. Organizational Dynamics, 24(4): 19-32

Schneider B, White S S, Paul M C (1998). Linking service climate and customer perceptions of service quality: Tests of a causal model. Journal of Applied Psychology, 83: 15-163

Scott S G, Bruce R A (1994). Determinants of innovative behavior: A path model of individual innovation in the workplace. Academy of Management Journal, 37(3): 580-607

Seibert S E, Silver S R, Randolph W A (2004). Taking empowerment to the next level: A multiple-level model of empowerment, performance, and satisfaction. Academy of Management Journal, 47: 332-349

Sobel M E (1982). Asymptotic confidence intervals for indirect effects in structural equation models. In: Leinhardt S (ed.), Sociological Methodology. Washington DC: American Sociological Association, 290-312

Sosik J J, Kahai S S, Avolio B J (1998). Transformational leadership and dimensions of creativity: Motivating idea generation in computer-mediated groups. Creativity Research Journal, 11(2): 111-121

Spreitzer G M (1992). When organizations dare: The dynamics of individual empowerment in the workplace. University of Michigan, unpublished doctoral dissertation

Spreitzer G M (1995a). Psychological empowerment in the work place: Construct definition, 
measurement, and validation. Academy of Management Journal, 38: 1442-1465.

Spreitzer G M (1995b). An empirical test of a comprehensive model of intrapersonal empowerment in the workplace. American Journal of Community Psychology, 23(5): $601-629$

Spreitzer G M (1996). Social structural characteristics of psychological empowerment. Academy of Management Journal, 39: 483-504

Spreitzer G M, DeJanasz S C, Quinn R E (1999). Empowered to lead: The role of psychological empowerment in leadership. Journal of Organizational Behavior, 20: 511-526 Spreitzer G M, Kizilos M A, Nason S W (1997). A dimensional analysis of the relationship between psychological empowerment and effectiveness, satisfaction, and strain. Journal of Management, 23: 679-704

Thomas K W, Velthouse B A (1990). Cognitive elements of empowerment: An "interpretive" model of intrinsic task motivation. Academy of Management Review, 15: 666-681

Tierney P, Farmer S M, Graen G B (1999). An examination of leadership and employee creativity: The relevance of traits and relationships. Personnel Psychology, 52: 591-620

Yammarino F J, Dionne S D, Chun J U, Dansereau F (2005). Leadership and levels of analysis: A state-of-the-science review. The Leadership Quarterly, 16: 879-919 